\title{
"Faz um filme com a gente, pra gente mostrar para os parentes": A cultura do povo Ka'apor acionada pelo cinema.
}

\author{
Alessandro Ricardo Pinto Campos \\ Universidade Federal do Pará, Brasil
}

\begin{abstract}
During one of my field trips while developing my doctoral research in Anthropology - about the war histories of the Ka'apor people - in the Axinguirendá village in the northeastern state of Brazil, I held a small Film Show that lasted three nights. From the films shown, all indigenous and / or produced by them, the culture and the pride of this people was strongly triggered by the images projected when leaders of the village propose to me the production of a small film from the script entirely elaborated by them : going to the countryside, cooking of mandiocaba, dispute of bow and arrow in the green papaya, corporal paintings made with urucum, dances and songs. Things that have not been doing for a long time, motives and desires that have been intensified by the viewing of films produced by relatives of other ethnic groups and cultures. The potential of the audiovisual is exposed and evidenced in this interesting experience inspired by the Shared Anthropology of Jean Rouch and the project Video in the Villages, by Vincent Carelli.
\end{abstract}

Keywords: Ka'apor People, Indigenous Culture, Movie Theater, Shared Anthropology, Jean Rouch

\section{Introdução}

Durante uma de minhas estadas em campo enquanto desenvolvia minha pesquisa de doutoramento em Antropologia - acerca das histórias de guerra do povo Ka'apor - na aldeia Axinguirendá no estado do Maranhão região nordeste do Brasil, realizei uma pequena Mostra de Cinema que durou três noites. A partir dos filmes exibidos, todos com temática indígenas e/ou produzidos por estes, a cultura e o orgulho deste povo foi fortemente acionada pelas imagens projetadas quando lideranças da aldeia me propõem a produção de um pequeno filme a partir do roteiro inteiramente elaborado por eles: ida a roça, cozimento de mandiocaba, disputa de arco e flecha no mamão verde, pinturas corporais feitas com urucum, danças e cantos. Coisas que não faziam há tempos, motivos e vontades recrudescidas a partir da visualização dos filmes produzidos por parentes de outras etnias e culturas. A potencialidade do audiovisual é exposta e evidenciada nesta interessante experiência inspirada pela Antropologia Compartilhada de Jean Rouch e pelo projeto Vídeo nas Aldeias, de Vincent Carelli.

\section{O povo Ka'apor}

A Aldeia Axinguirendá está localizada no estado do Maranhão, estado vizinho do Pará, na região nordeste do Brasil, fazendo parte da região amazônica. Fica a $25 \mathrm{~km}$ do município de Centro do Guilherme. Esta aldeia faz parte da Terra Indígena Alto Turiaçu (que tem uma extensão total de 530.525 hectares) esta Terra Indígena ( $\mathrm{TI})$ é demarcada pela Funai desde 1978 e foi homologada através do decreto $N^{\circ} 88.002$ em 1982. É a segunda maior aldeia da etnia Ka'apor, possui 104 famílias e cerca de 520 habitantes segundo Censo de 2015 (só é menos populosa que a aldeia Ximborendá, com 720 habitantes).

$\mathrm{Na}$ sua língua do tronco Tupi, a palavra Ka'apor, significa "gente que mora na mata" (Balée, 1993; Ribeiro, 1976). Esta TI compreende parte dos municípios de Araguanã, Centro Guilherme, Centro Novo do Maranhão, Maranhãozinho, Nova Olinda do Maranhão, Santa Luzia do Paruá e Zé Doca, perfazendo uma extensão de $5.304 \mathrm{~km} 2$. Os Ka'apor dividem esse território com outros povos, estabelecendo relações próximas como casamentos interétnicos e também de conflito, são eles os Tembé, Awa-Guajá, (também de língua Tupi) e os Timbira (de língua Jê) (López Garcés et al., 2015). Na figura 01, a seguir, observa-se a localização geográfica dessa TI.

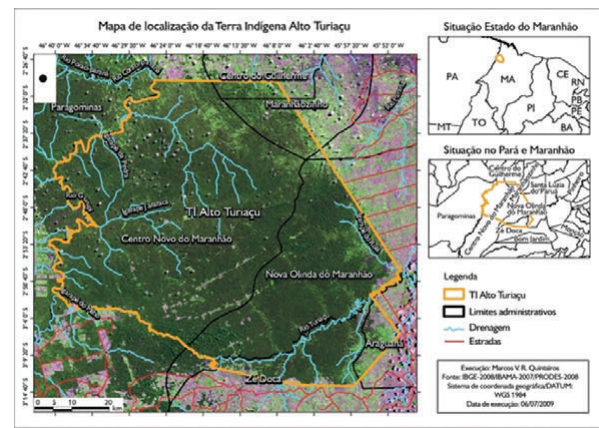

Figura 1 - Mapa de localização da Terra Indígena Alto Turiaçu. Fonte: Bol. Mus. Para. Emílio Goeldi. Ciênc. hum. vol.11 no.1 Belém Jan./Apr. 2016. Disponível em: http://www.scielo.br/ scielo.php?script=sci_arttext\&pid=S1981-81222016000100133. Data de acesso: 28/07/ 2017.

Ao longo dos tempos, toda esta região tem sido cenário de conflitos interétnicos provocados sempre por invasões dos territórios indígenas por não indígenas. Ainda no século XIX, esses conflitos estavam vinculados à intensificação não controlada de economias extrativas, tais como garimpo de metais preciosos. Cabe ressaltar que a esta atividade extrativista soma-se a sempre presente exploração madeireira e pecuária. Em 1873 estes episódios forçaram o deslocamento dos Ka'apor da região do rio Piriá, onde viviam, para a região do rio Gurupi onde estão atualmente (Balée, 2005 apud López Garcés, 2016).

Na região dos rios Turiaçu e Gurupi, já no século $\mathrm{XX}$, aconteceram muitos conflitos entre os Ka'apor e moradores locais que exploravam madeira, seringa e 
óleo de copaíba, com fazendeiros e os trabalhadores das linhas telegráficas. Alguns desses episódios foram macabros, como: empalar cabeças de alguns Ka'apor próximas a essas linhas, como aviso para que não mais as derrubassem (de Figueiredo, 2013, López Garcés et al., 2015). Na tentativa de pacificar esses índios urubus considerados muito violentos, em 1911, o Serviço de Proteção aos Índios (SPI) criou o Posto Felipe Camarão, no igarapé Jararaca. O Posto Pedro Dantas, responsável pela "pacificação" dos Ka'apor, criado em 1928, também foi responsável por várias doenças de branco, como uma epidemia de gripe vitimando boa parte desta população (Ribeiro, 2006). Samain também relata essas dificuldades pelas quais passaram os Ka'apor:

Já no final do século passado, os Ka'apor, vitimados por várias epidemias, tinham-se retirado do lado maranhense e atacavam esporadicamente as frentes extrativistas (garimpeiros e madeireiros em particular) situadas entre os Rio Gurupi e Turiaçu. Darcy Ribeiro retratou, com base em uma documentação de primeira mão, a história da "pacificação" que se seguiu. Iniciada em 1911, pelo SPI (Serviço de Proteção aos Índios) ela havia de se concretizar somente em dezembro de 1928, ameaçada, no entanto, logo depois (1929), pela morte violenta do capataz Benedito Jesus de Araújo no Posto "Pedro Dantas", atual Posto Indígena de Canindé. (Samain, 1984, p. 102).

Mais problemas estavam reservados aos Ka'apor, como todo povo indígena no Brasil, e no continente americano como um todo, sempre enfrentando ondas cíclicas de traumas e violências proporcionadas em nome 'progresso e da ganância', desta vez:

As dinâmicas de expansão da fronteira agropecuária e madeireira no Maranhão começam a se consolidar a partir da década de 1960, com a construção da via Belém- Brasília (Moura et al., 2011). A abertura da via BR-222, que conecta a rodovia Belém-Brasília com São Luís, a capital do estado, gerou dinâmicas de avanço sobre as florestas primárias da Amazônia maranhense, promovendo 0 surgimento de pequenos povoados, hoje convertidos em municípios (Moura et al., 2011). Segundo Almeida et al. (2005), nesta mesma década inicia-se também um processo acelerado de desmatamento, associado à produção pecuária para carne de exportação, cultivo de soja, plantações de eucalipto para produção de celulose, exploração madeireira e atividades de mineração. $\mathrm{Na}$ década de 1980, os Ka'por enfrentaram um processo de intensificação dos conflitos territoriais, quando cerca de 1.300 posseiros e madeireiros invadiram a Terra Indígena Alto Turiaçu, inclusive após sua demarcação e reconhecimento, em 1981, assim como também a Reserva Biológica Gurupi, extraindo grandes quantidades de madeira, especialmente de pau d'arco (Tabebuia sp.). $\mathrm{Na}$ década de 1990, houve ataques às aldeias indígenas por parte de posseiros e madeireiros e contraataques dos Ka'apor aos acampamentos e serrarias estabelecidos ilegalmente dentro da Terra Indígena (Balée, 2005). A luta pela defesa da Terra Indígena Alto Turiaçu permanece na memória dos Ka'apor como um evento histórico de grande impacto na sua vida. (López Garcés, 2016. pag. 137)
Estes inúmeros conflitos forçaram outros deslocamentos dentro da Terra Indígena dos Ka'apor. $\mathrm{Na}$ intenção de proteger e vigiar sua terra, novas aldeias foram criadas em locais estratégicos, como é o caso das Xie-Pihu-rena e Paracui-rena em 2002 e a Axinguirendá em 2003, aldeia onde desenvolvo minha pesquisa de doutoramento pelo Programa de pós-graduação em Sociologia e Antropologia pela Universidade Federal do Pará.

\section{A experiência de um caso concreto: a potencialidade do audiovisual}

Em meados de julho de 2017, em uma de minhas idas a campo passei 15 dias na aldeia Axinguirendá, onde desenvolvo minha pesquisa de doutoramento. Nela. Interesso-me pelas histórias de guerra desse povo, historicamente aguerrido e profundamente ligado às contendas e a recentes substituições destas pela política e negociação, fortalecida pela Associação Ka'apor Ta Hury do Rio Gurupi. Busco nesta investigação unir o passado e o presente para refletir os modos operacionais e estratégicos de sobrevivência de uma comunidade humana. Antes estreitamente lifada a guerra e hoje profundamente políticas.

Paralelamente à pesquisa, durante esta estadia, fiz uma pequena mostra de cinema indígena na aldeia. $\mathrm{Na}$ Ohú (casa comunal da aldeia, onde acontecem as reuniões, as festas e cerimônias dos moradores) com um projetor, caixa amplificada e tela de projeção, exibi filmes por três noites consecutivas sempre com sessões lotadas e muito animadas. O filme principal foi feito por Heinz Foerthmann, cineasta alemão que esteve junto com Darcy Ribeiro nos anos de 1940/1950 entre eles, os Ka'apor, em outras aldeias. Seu filme intitulado Os índios Urubus: A vida diária numa aldeia indígena da floresta tropical de 1949, é um filme em preto e branco e mudo, tem a duração de 40 minutos onde seus atores 'encenam sua vida própria vida cotidiana' (pescando, caçando, fabricando arco e flecha, fazendo farinha ou simplesmente deitados na rede a descansar e conversar...) feito nos moldes da época (segundo Darcy Ribeiro em seu livro Diários índios... (1975) era uma verdadeira peleja para convencer aos 'indígenas atores' que não deveriam olhar para a câmera, por dezenas de vezes as cenas foram refeitas). Com uma carga etnográfica fantástica, me interessava exibir esse filme aos Ka'apor: um filme feito com/sobre eles que jamais haviam tido acesso. Coisa que me perturba é o acesso ainda incipiente dos indígenas aos filmes que são feitos com eles.

Nessa Mostra foram exibidos filmes do Projeto, de Vincent Carelli, Vídeo nas Aldeias. Filmes feitos por parentes de outras etnias mostrando suas culturas, o que muito interessou minha plateia sempre atenta às apresentações.

No segundo dia de exibições, recebi a visita de lideranças da aldeia em meu alojamento logo no início da manhã. Fernando, Diquixim, Ximí e Valdir me fazem, enfaticamente, um pedido: "Faz um filme com a gente, pra gente mostrar para os parentes", queriam fazer um filme "como os parentes fizeram, igual 
aqueles que a gente viu ontem"... Queriam também poder mostrar sua cultura para todo o mundo, se fazer conhecer. Feliz, surpreso (nem tanto, pois meu ato não foi totalmente desinteressado - nenhum é, como disse Mauss ${ }^{1}$ ) e um pouco preocupado pois só havia levado um cartão de memória de $16 \mathrm{gb}$, que já havia se mostrado problemático, aceitei de pronto a proposta.

Durante a noite, aconteceu uma Reunião de Planejamento. Lideranças e outros moradores da aldeia reuniram-se na Ohú para tratar exclusivamente do filme. Depois de alguma discussão chegaram a um consenso sobre como seria, efetivamente, o filme deles. Seria feito uma mandiocaba, uma bebida doce feita a partir de um tubérculo semelhante à mandioca, ralado e fervido seu caldo. Eu iria filmar todo o processo de fabricação desta bebida: desde a ida à roça, arrancar a mandiocaba, descascar, ralar, ferver. Também aconteceriam disputas de arco e flecha no mamão verde, pinturas corporais feitas com urucum (isso foi muito enfatizado por eles, pois a pintura ka'apor verdadeira é feita com urucum² ${ }^{2}$ e não com jenipapo, muito comum na aldeia. Esta última teria sido uma influência dos Tembé, povo muito amigo e próximo deles), entoariam cantos e dançariam: homens e mulheres.

$\mathrm{E} O$ filme retrata exatamente isso. O que eles queriam mostrar, nada aconteceu a partir de um pedido meu, nenhum arranjo ou rearranjo. Todo o roteiro foi feito por eles, o que torna a coisa mais interessante. Pois foi tudo o inverso do que costuma acontecer: eu não fui filmar uma celebração que já iria acontecer, mas a celebração só aconteceu para que pudesse ser filmada. Tudo foi pensado e criado, para virar um filme e ser mostrado e divulgado. Eles queriam como nos filmes exibidos de outros parentes, ter uma produção própria, mostrar e divulgar sua cultura.

E assim foi feito o filme. Seguindo o que France (1998, p. 339) chama de modelo Exploração, ela aponta que é fundamental "a ideia de uma estreita colaboração entre o cineasta e as pessoas filmadas, a partir da observação compartilhada da imagem". Efetivamente.

A filmagem começa logo cedo, pela manhã, após uma breve discussão, é decidido de qual roça será arrancada a mandiocaba. Eles me levam para ohú e espero um pouco. Se preparam e os sigo para a roça de Valdir, longe 3 quilômetros da aldeia, uma liderança da aldeia e enfermeiro do posto de saúde. Faço bons planos e os acompanho a trupe de crianças e mulheres nesta primeira parte do filme. Com o jamaxim ${ }^{3}$ cheio retornamos para a aldeia, onde outra equipe descasca e põe-se a ralar o tubérculo. O resultado disto é espremido e coado. O fogo está pronto e a panela é colocada. Jovens meninos carregados de madeira da mata alimentam o fogo. Claramente há uma divisão sexual do trabalho.

Pelas $15 \mathrm{~h}$ outras lideranças da aldeia começam a chegar na ohú, onde tudo está acontecendo. Usam minha caixa amplificada e plugam um microfone barulhento nela, na língua ka'apor fazem o chamado para toda aldeia que, traduzido, é mais ou menos isso: "venham todos para ohú, estamos fazendo um filme como aqueles que vimos ontem. Tragam seus arcos e suas flechas, vamos brincar no mamão verde, como nossos pais faziam. Vamos nos pintar de urucum, e não de jenipapo. Vamos cantar e dançar, tomar mandiocaba gostosa. Estamos fazendo um filme com o Alessandro. Venham todos!"

Logo a ohú está cheia com os moradores da aldeia obedecendo ao chamado. Crianças e velhos, meninos e meninas vão chegando. Jovens começam a disputar alegremente quem acerta o mamão verde com a flecha. Todos se pintam com urucum arrancado da árvore naquela tarde. Conversas animadas. Risadas e brincadeiras fazem tudo ser divertido. A câmera, que vai passeando entre eles, não os inibe. Querem aparecer, querem ter um filme, me chamam para aparecer e fazem poses. É um filme deles, efetivamente.

As lideranças se revezam no microfone mantendo o chamado ativo. A tarde vai passando num ritmo suave e estamos, todos, felizes. Os homens se juntam para dançar, cantam, se dão as mãos. Logo é a vez das mulheres de cantarem. A mandiocaba está pronta e é servida em copos de plástico (emprestados da escola da aldeia) junto com um pedaço de carne assada. Mais animação. Mais risos. Já no início da noite, as pessoas vão se dispersando, sem pressa. Ximí, o cacique da aldeia, me chama num canto e diz: "Alessân, vai ter filme hoje? Todos querem ver filme". Eu respondo: "Sim, vai. Vou só buscar as coisas, tá?". No dia seguinte, pela manhã, ainda faço a filmagem final, onde o cacique e outros moradores explicam o que querem com o filme, falam na língua ka'apor e depois em português diretamente para a câmera no tripé, resumindo é: "Nós somos ka'apor, essa é nossa aldeia, essa é uma mostra da nossa cultura. Queremos mostrar para todo o mundo. Nós vamos fazer outros filmes, e nestes vamos estar mais preparados, com enfeites nos homens e nas mulheres, nas crianças também. Até breve!"

O interessante dessa experiência foi que tudo isso foi acionado, instigado e desejado a partir da exibição dos filmes, durante nossa pequena Mostra na Ohú, iniciado dois dias antes. O orgulho da cultura, o desejo de registrá-la e mostrá-la, a consciência e certa tristeza de que já não possuem as riquíssimas artes plumárias com as quais são mundialmente famosos (fica claro nas imagens do filme e no discurso final do cacique Ximí: "da próxima vez todos estarão mais enfeitados, homens, mulheres, jovens e crianças...”). Ao verem o filme feito por Heinz Foerthmann, com seus parentes de décadas atrás, se deram conta do quanto estão diferentes, principalmente pela ausência de sua arte plumária e, ao mesmo tempo, viram nos demais filmes outros parentes de outras etnias celebrando suas culturas, algum sentimento foi acionado/despertado, surgindo a necessidade de mostrar a sua também: "essa é uma pequena mostra da nossa cultura Ka'apor".

Quando perguntei quando teria acontecido a última celebração feita como aquela, não souberam responder. Mas já havia um bom tempo que não faziam aquelas coisas. Esse retorno, essa preocupação em fazer tudo isso, foi criado/acionado a partir dos filmes. O poder do audiovisual, o que não é nenhuma 
novidade, é realmente fascinante. A seguir alguns frames do filme que está sendo finalizado.

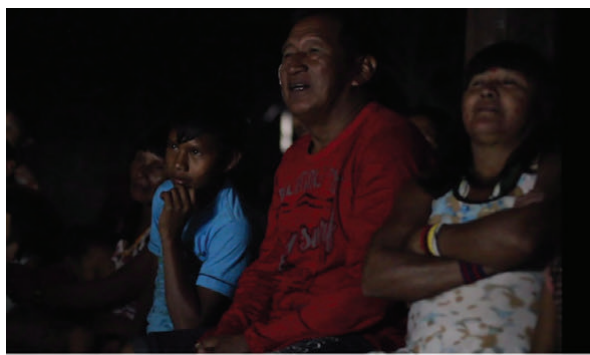

Figura 2 - A plateia atenta assiste a Mostra de Cinema Indígena na Ohú.

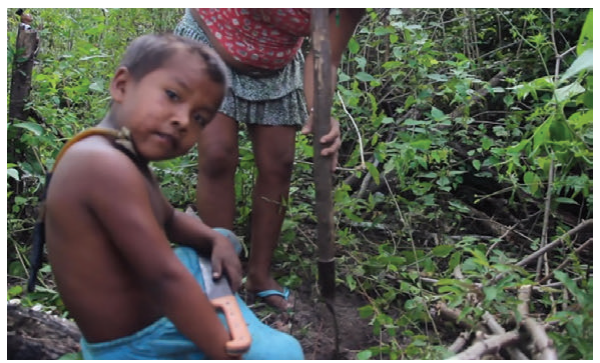

Figura 3 - Menino Ka'apor ajuda a arrancar mandiocaba para a 'festa inventada'.

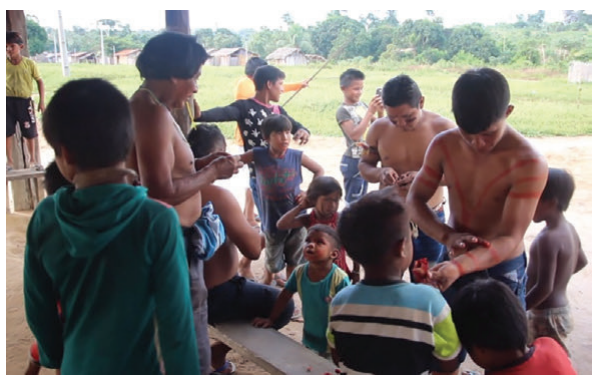

Figura 4 - Hora da pintura corporal feita com urucum. Sua cultura sendo repensada.

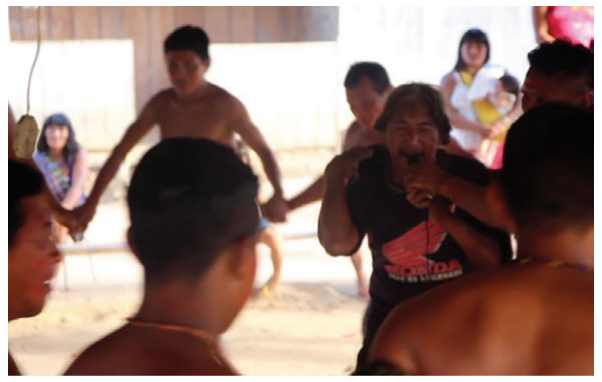

Figura 5 - a dança dos homens, na ohú. Tãmpí, um dos mais velhos da aldeia assume o microfone.

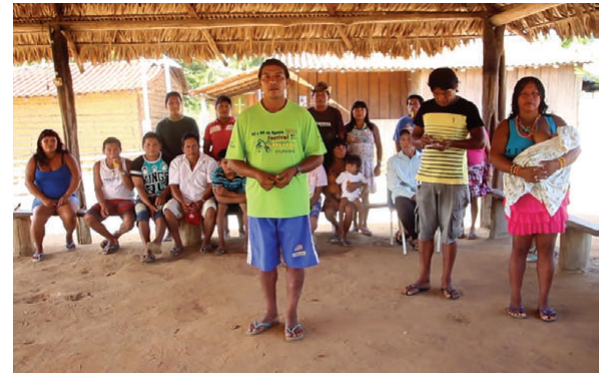

Figura 6 - Ximí, o cacique da aldeia, explica no final do filme o sentido do filme pensado por eles: "essa é uma pequena mostra da nossa cultura que queremos mostrar..."

\section{Desdobramentos}

Toda essa experiência com a aproximação deles com a produção fílmica me fez escrever um projeto e concorrer ao edital da Pró-reitoria de Extensão da Universidade Federal do Pará - PROEX/UFPA, sob o título "Axinguirendá audiovisual" onde fui um dos vencedores em 2018. O projeto consiste em uma oficina de produção audiovisual para 15 pessoas do povo Ka'apor, além da entrega de equipamento básico para que possam começar a produzir (câmera, tripé, microfone, notebook).

A intenção é que em breve eles mesmos possam fazer seus próprios filmes, sem a ajuda de um branco. Suas festas, rituais... o que mais eles quiserem. Eles são os protagonistas da própria história.

\section{Inspirações}

\section{O projeto Vídeo nas Aldeias de Vincent Carelli}

O projeto Vídeo nas Aldeias foi criado em 1987 por Vincent Carelli, cineasta e ativista realizador de dezenas de filmes e premiado mundialmente em vários festivais, foi o pioneiro na área de produção audiovisual indígena no Brasil, a partir do qual a produção compartilhada com os povos indígenas tornava-se uma narrativa poderosa de apoio a esses povos no intuito de "fortalecer suas identidades e seus patrimônios territoriais e culturais". Essa experiência começa dentro das atividades da Organização Não Governamental "Centro de Trabalho Indigenista" onde Carelli fazia parte, e a história da produção audiovisual indígena no Brasil jamais seria a mesma.

Este fabuloso projeto se inicia entre os índios Nambiquara, com a experiência de filmá-los e deixálos assistir o que foi filmado, isso foi gerando uma mobilização interna, entre os próprios indígenas, um interesse crescente pela produção feita entre eles. 0 aparecimento das produções audiovisuais indígenas despertou o surgimento de uma "audiência" nativa, mas isso não ocasionou o fim do interesse deles pela produção televisiva. As telenovelas e a transmissão de partidas de futebol estão entre os principais programas na preferência dos índios nas aldeias. Diante do potencial que o instrumento apresentava, 
esta experiência foi sendo levada a outros grupos e gerando uma série de vídeo sobre como cada povo incorporava o vídeo de uma maneira particular.

A primeira oficina de formação audiovisual indígena do projeto acontece naAldeia Xavante de Sangradouro, em Mato Grosso, em 1997. São distribuídas ente os futuros cineastas indígenas equipamentos de exibição câmeras, iniciando a formação de novos produtores. É o início de uma nova geração de realizadores indígenas, fazendo com que mude profundamente a forma de registrar e narrar as suas manifestações culturais garantindo seu protagonismo nos filmes que, até pouco tempo atrás, era exclusivo de etnógrafos e pesquisadores nas imagens e roteiros.

A forte vocação oral dos povos indígenas contribui para o sucesso do audiovisual entre eles, já que entre as tecnologias comunicativas existentes (rádio, literatura e internet), o vídeo é a que eles mais absorvem e incorporam como poderosa mediação cultural. As explicações são as mais diversas e, certamente, as principais se devem às características inerentes à linguagem audiovisual, entre as quais, a capacidade expressiva das imagens de englobar o fundamental da comunicação indígena: a oralidade e a corporalidade. Da tela de uma TV vê-se o mundo como num sonho coletivo onde a imaginação é captada pelos olhos e pelos sentidos: tecno-magia. Do esplendor da TV à força arrebatadora e irresistível das imagens em movimento, geradora de curiosidade coletiva nas aldeias indígenas, repercute, aos poucos, uma nova forma de olhar e de vivenciar um tempo diverso, aquele da reprodução visual. Tudo isso sem a necessidade de alfabetização prévia. (Pereira, 2010. p.66).

A experiência da difusão efetiva da mídia audiovisual nas sociedades indígenas foi disponibilizada e instrumentalizada pela antiga política colonial do Brasil exclusivamente como um veículo de divulgação e disseminação da ideologia e da língua, com clara intenção de difundir e potencializar a sociedade branca nestes espaços. Com o passar do tempo esse plano se mostrou claramente inverso, uma vez que os indígenas acabaram se apropriando desta tecnologia em causa própria, e de muitas outras. $E$ mais que isso: estas novas tecnologias acabaram se incorporando ao seu vasto arsenal de luta e ela valorização de sua cultura sempre ameaçada pelos não indígenas.

Essa apropriação tecnológica também acaba contribuindo para diminuir o preconceito e a ignorância que a questão indígena sempre foi tratada no Brasil, desde os livros didáticos e as figuras simplificadas e rasas de suas culturas, a ganância e violência nas questões das Terras Indígenas - o povo Ka'apor vem sofrendo uma serie de violências e invasões de suas terras que se agravaram nas última década, madeireiros e garimpeiros invadem suas terras e o histórico de confrontos é vasto. Após a eleição do atual presidente Jair Bolsonaro, abertamente contrário à questão indígena, o país enfrenta um episódio particularmente triste e preocupante no cenário político atual.

Cada povo tem sua forma de apreender e utilizar recursos audiovisuais, e essas diferenças evocam a própria percepção deles e de sua cultura. Sem dívida, este projeto é o grande responsável por uma profunda transformação na produção audiovisual indígena no Brasil. A partir desta já vasta produção, as narrativas orais, características culturais dos povos indígenas brasileiros, puderam efetivamente sair da Terra Indígena e ganhar o mundo.

Os temas escolhidos para os filmes são os mais variados. Pode estar submetido aos interesses e às lutas políticas internas e externas, principalmente a questão de posse da terra e invasão de fazendeiros e madeireiros, ainda comum. Pode tratar de um mito, uma cerimônia, uma festa. O que importa é que são eles que escolhem o tema, são os protagonistas e produtores dos filmes, não mais o branco, o de fora, o não indigena que chega para fazer seus filmes e muitas vezes os filmados nunca chegam a se ver na tela.

A eficácia das imagens equivale para eles à presença. Eles apostam no vídeo muito mais que em outras tecnologias comunicativas, porque as imagens em movimento parecem lhes proporcionar a perenidade coletiva e existencial - a memória do grupo pode ser transmitida às futuras gerações, principalmente a memória dos velhos, os guardiões das suas narrativas. (Pereira, 2010. p.70).

Por todas essas razões, o projeto pensado por Vincent Carelli - importante cineasta indigenista a quem tive a honra de conhecer quando este foi o grande homenageado durante I Festival do Filme Etnográfico do Pará ${ }^{4}$ em 2017 - Vídeo nas Aldeias serviu de base para minhas ações, desde o início, quando pensei na Mostra de Cinema indígena na aldeia Axinguirendá. Eu suspeitava que esses filmes despertariam desejos e curiosidades nos moradores de lá. Percebi como já manuseavam celulares e produziam pequenos vídeos de suas brincadeiras cotidianas, reuniões políticas e festas cerimoniais. Acredito, que faltava lhes apresentar produções feitas por parentes de outras etnias, para que pudessem conhecer e acreditar que produções como aquelas são possíveis de serem realizadas.

Acredito, ainda, que se iniciará um novo momento para o povo Ka'apor. De se representarem a si mesmos da forma que quiserem, sem a intervenção, ou tutela, de 'gente de fora'. Eles só precisam dominar as tecnologias necessárias para que possam protagonizar, efetivamente, seus filmes, suas histórias, suas memórias, suas vozes e imagens ecoando e exibindo sua diversidade, sua cultura, suas lutas, suas resistências, suas vidas.

\section{Pensando em Jean Rouch}

De tantas influências que se pode ter de Jean Rouch, esse híbrido de antropólogo e cineasta, a que mais costumo levar a campo é a antropologia compartilhada e dialética do cinema-verdade, esta verdade encenada, numa via de mão dupla.

Ele sempre tentou colocar o antropólogo também na posição de observado tentando inverter posturas 
comuns desta disciplina - que na sua origem trabalhou claramente para o colonialismo - hibridizando alteridades como as do antropólogo/cineasta e nativo, deixando de ver o outro como objeto e sim como sujeito. Ele pensou em todas essas questões mesmo antes do que se chamaria de antropologia pós-moderna, se caracterizando como alguém a frente de seu tempo.

Rouch inova em suas experiências e etnografias imagéticas, a grande maioria realizada no continente africano. Caracterizando o que chama de antropologia compartilhada, na qual o pesquisador/antropólogo, de modo efetivo e verdadeiro, interage com o nativo, com o informante, com o outro - por excelência - a ponto de desconstruir ideias de autoridade etnográfica em função de uma intersubjetividade, que sempre buscou. Para Rouch, "O outro é simplesmente outro, não é objeto de estudo, é sujeito, e, antes de tudo, um amigo em potencial" (Gonçalves, p. 21).

Pensar no método de Rouch é pensar na relação de intimidade/cumplicidade e respeito que se tem, ou se deveria ter, em campo e em qualquer pesquisa, tratando todos como iguais, fugindo da relação assimétrica que costuma acontecer entre pesquisador e pesquisado.

Podemos considerar os filmes produzidos por Jean Rouch, como parte de uma nova reflexão epistemológica sobre a qualidade e a condição da etnografia e do cinema, envolvendo uma série de questões relevantes à ciência antropológica, "assim, o cinema de Rouch se inspira nos conceitos da Antropologia e sua Antropologia está inspirada na sua percepção das imagens e do cinema." (Gonçalves 2008: 22).

É Rouch que, de certa forma, inaugura questionamentos quanto ao lugar do outro na pesquisa antropológica, da postura do antropólogo, da objetividade, da subjetividade, do real, do ficcional, da alteridade, do trabalho de campo responsável e da produção de conhecimento.

Acredito que a experiência da produção do filme na aldeia Axinguirendá, evidencia a dialética do cinemaverdade Rouchiano: a da verdade da encenação e vice-versa. Quando os ka'apor decidem fazer uma festa inventada (pois ela não fazia parte de seu calendário de cerimônias) apenas para que pudesse ser feito o filme, pude presenciar de forma concreta a "encenação real", pensada e "fingida" com o único proposito da filmagem, nas palavras de Rouch, o que realmente importa é «A verdade do cinema e não a verdade no cinema».

É fingida, mas é real, e vice-versa - é tudo mentira, é tudo verdade - primeiro porque apesar de não fazer parte de seu calendário oficial, tudo aquilo que eles estavam fazendo faz parte de seu arcabouço cultural, de seu arsenal de tradições e que foi acionado a partir da Mostra de Cinema Indígena. Os filmes feitos por seus parentes foi a inspiração que precisavam, seu orgulho foi "ferido" por ainda não terem feito nada parecido com aquilo. Eles também querem ser vistos, ouvidos e conhecidos.

\section{Notas Finais}

${ }^{1}$ Ensaio sobre a Dádiva (1998).

${ }^{2}$ Fruto do urucuzeiro (Bixa orellana) são capsulas com sementes envoltas por coloração vermelha usada em corantes.

${ }^{3}$ Cesto feito de tala e cipó, usado para carregar mandioca e outras coisas.

${ }^{4}$ A primeira edição aconteceu em 2017, e para este ano acontece o II Festival. Para mais informações visitar www. festivaldopara.com.br

\section{Bibliografia}

France, Claudine de. Cinema e Antropologia .Campinas: Editora da Unicamp, 1998.

Gonçalves, Marco Antônio. O real imaginado Etnografia, cinema e surrealismo em Jean Rouch, Rio de Janeiro: Topbooks, 2008.

López Garcés, Claudia Leonor. O mundo da horticultura Ka'apor: práticas, representações e as suas transformações. Boletim do Museu Paraense Emílio Goeldi. Ciências Humanas, v. 11, n. 1, jan.-abr. 2016: 133158.

Pereira, Eliete da Silva. Mídias Nativas: a comunicação audiovisual indígena - o caso do projeto Vídeo Nas Aldeias. Revista CiberLegenda - UFF, 2010. p. 62-72.

Ribeiro, José da Silva. "Jean Rouch - Filme etnográfico e Antropologia Visual" in Doc On-line, n.03, Dezembro 2007, www.doc.ubi.pt: 6-54.

Ribeiro, Darcy. Diários Índios: os Urubu-Kaapor. Companhia das Letras, $1^{\circ}$ edição. 1996.

Samain, Etienne. "A vontade de Ser: notas sobre os índios Urubu Ka'apor e sua mitologia" in Revista de Antropologia, volumes 27/28. Departamento de Ciências sócias da Faculdade de Filosofia, letras e ciências humanas da Universidade de São Paulo. Brasil. 1984/1985: 68-109. 